\title{
THE GENESIS OF EDWARD JENNER'S INQUIRY OF 1798: A COMPARISON OF THE TWO UNPUBLISHED MANUSCRIPTS AND THE PUBLISHED VERSION
}

by

\section{DERRICK BAXBY*}

Edward Jenner continues to be a controversial figure in medical history and his role in the introduction of smallpox vaccination is still debated. Those interested in the development of Jenner's ideas on smallpox prophylaxis will know that two manuscripts exist which contain much of what was to be incorporated into his famous monograph, privately published in $1798 .^{1}$

One manuscript (here designated RC-MS), in the possession of the Royal College of Surgeons of England, was compared to the published Inquiry by E. M. Crookshank, ${ }^{2}$ and the text was later published to commemorate the centenary of Jenner's death. ${ }^{3}$ Unfortunately, both these analyses omit note of virtually all the important features that make them of value to those interested in the development of Jenner's ideas. The second manuscript (WI-MS), in the possession of the Wellcome Institute for the History of Medicine, has never been published.

The present paper briefly summarizes the main features of interest of the two manuscripts and traces the development of Jenner's principal theories through to the published Inquiry. ${ }^{4}$

\section{THE WELLCOME INSTITUTE MANUSCRIPT ${ }^{5}$}

This manuscript is in the form of a bound notebook, and was written out for Jenner by a relative, William Davies. There are numerous additions and alterations in Jenner's hand throughout the text, which is signed and dated 29 March 1797. There are also three pages of notes in Jenner's hand after the text proper. Because the text is not in Jenner's hand, his alterations and additions can be seen as deliberate afterthoughts, rather than instant corrections.

*Derrick Baxby, BSc, PhD, Senior Lecturer in Medical Microbiology, University of Liverpool, PO Box 147, Liverpool L69 3BX.

${ }^{1}$ Edward Jenner, An inquiry into the causes and effects of the variolae vaccinae, London, Sampson Low, 1798; Jenner Centenary Number, Br. med. J., 1896, i: 1245-1312, p. 1257; William LeFanu, Bio-bibliography of Edward Jenner 1749-1823, 1st ed., London, Harvey \& Blyth, 1951, pp. 22-24; 2nd ed., London, St. Paul's Bibliographies, [in press, 1985].

${ }^{2}$ Edgar M. Crookshank, History and pathology of vaccination, 2 vols., London, H. K. Lewis, 1889 ; vol. 1 pp. 250-265; vol. 2 pp. 1-33.

3 [Edward Jenner], 'An inquiry into the natural history of a disease known in Glostershire by the name of the cow-pox', Lancet, 1923, i: 137-141.

Copies of a more detailed comparison have been lodged in the libraries of the Wellcome Institute (ref. pamB/JEN), and the Royal College of Surgeons of England, and in the Jenner Museum, Berkeley (ref. H.CRJEN).

${ }^{5}$ Edward Jenner, 'An inquiry into the natural history of a disease known in the Western counties of England particularly Glostershire by the name of the cow-pox', Wellcome manuscript 3019; LeFanu, op.cit., note 1 above. 


\section{Baxby}

The manuscript contains the account of the vaccination of James Phipps in 1796 and the latest case included is that of William Rodway who was variolated on 13 February 1797. However, the manuscript lacks the accounts of William Stinchcombe, Hester Walkley, and Sarah Nelmes, all of which could have been included. In fact, there are notes in Jenner's hand at the appropriate places to remind himself to add these cases. Interestingly, the note refers to "Lucy Nelmes", whereas in the published Inquiry she is "Sarah".

The Wellcome MS is particularly interesting because apparently Jenner showed it to a third party, who made some pencil comments on it. We know from Baron that Jenner discussed his proposed paper with colleagues, but the identity of this particular reviewer is unknown. ${ }^{6}$ However, the comments are valuable because they allow us to assess what evidence Jenner was prepared to show someone else, what this person thought of it, and how Jenner responded.

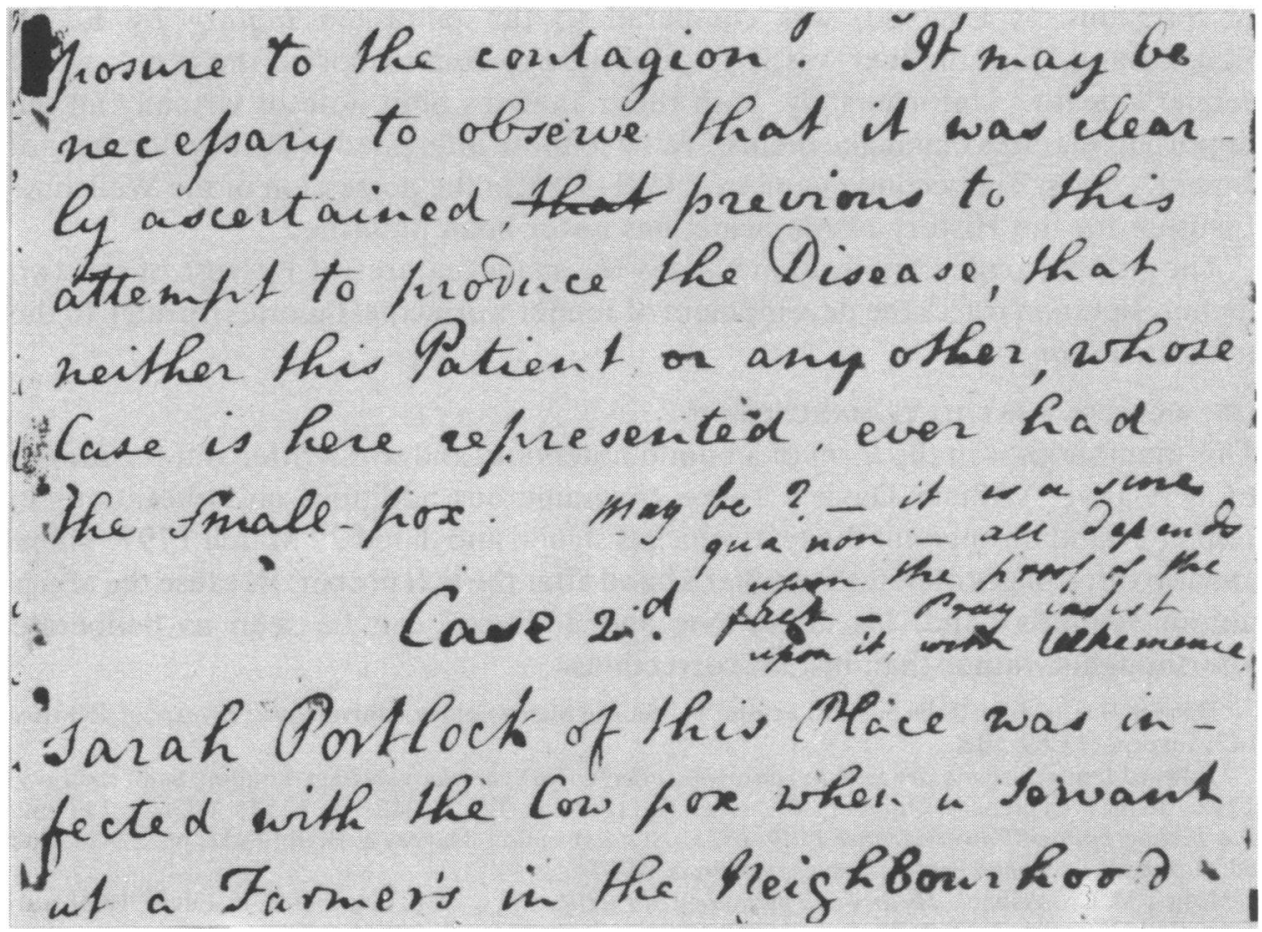

Figure 1. The important pencilled comment made by Jenner's unknown reviewer to p. 9 of the WI-MS. (Reproduced by courtesy of the Wellcome Trustees.)

'John Baron, Life of Edward Jenner, 2 vols., London, Colborn, 1838, vol. 1, p. 142. 
Many of the pencilled comments are minor complaints about spelling and grammar. Others are more important, in particular a comment on p. 9. Here, at the end of the account of Joseph Merrett (Case 1) Jenner wrote, "it may be necessary to observe" that none of the individuals "whose case is here represented have ever had the small-pox."'The pencilled comment, inked over by Jenner is "May be?-it is a sine qua non-all depends upon the proof of the fact-pray insist upon it with vehemence." (fig. 1). In the published Inquiry (p. 10) the passage is altered to make it more emphatic. "It is necessary to observe ... utmost care ... scrupulous precision" that no one had previously had smallpox. Jenner also added a paragraph indicating that he could not have made his observations in a large city where most people would have had smallpox.

Jenner responded to other pencilled comments on pp. 29, 30, and 44 by making certain passages clearer, although they are not as important as the one discussed above. Also of interest is the fact that in four places (pp. 7, 16, 30, 38) vague terms such as "this", "complaint" were replaced in pencil by "cowpox" (see below).

The Inquiry was improved as a result of Jenner's response to the pencilled comments, some of which were particularly valuable. ${ }^{7}$ However, it is important to note that the reviewer made no comment about Jenner's hypotheses nor about the evidence on which they were based. ${ }^{8}$

\section{THE ROYAL COLLEGE MANUSCRIPT}

This manuscript is in Jenner's hand and it is not always possible to determine which alterations were deliberate afterthought. The accounts of Stinchcombe, Walkley, and Nelmes are missing, but there is a reminder at the appropriate place to add the first two. There is a long footnote to Case 3 (John Phillips) which spreads over pp. 15-17. This evidently confused Jenner, because the next case (Mary Barge), which begins on p. 16, is also numbered Case 3. Consequently, case numbers from then onwards are incorrect.

Alterations by Jenner to case and page numbers from the original p. 20 onwards show that he added two more cases after the original version was completed. Close examination of the physical make-up of the notebook and of the text on the original pages which bracket the added leaves indicates that Jenner cut out a leaf which had carried the account of William Rodway (variolated 17 February 1797) and inserted leaves on which were written the cases of Sarah Wynne, Rodway, and Elizabeth Wynne. The Wynnes were variolated on 28 March 1787.

William LeFanu, who originally suggested that Sarah Wynne was in the original MS and that William Rodway was an added case, now agrees with the above interpretation..$^{10}$ Correct identification of the original cases is necessary in order to date the manuscripts (see below).

The RC-MS contains references to a "blue book" in which Jenner presumably

\footnotetext{
'Particularly Jenner's response to the "insist upon it" comment, and the increased use of the term "cowpox".

${ }^{8}$ It is possible that Jenner also received verbal comments.

'Edward Jenner, 'An inquiry into the natural history of a disease known in Glostershire by the name of the cow-pox', Royal College of Surgeons of England catalogue H. CRJEN; LeFanu, op. cit., note 1 above.

${ }^{10}$ Ibid.
} 


\section{Baxby}

kept detailed records of his cases, and also to a "print", possibly the illustration of the lesions on the hand of Sarah Nelmes, which was included in the published version.

\section{DATING AND RELATION OF THE TWO MANUSCRIPTS}

It is of interest to determine the sequence of preparation and correction of the manuscripts. Although the dates mentioned in them are useful, comparison of the additions and corrections is also necessary.

The Wellcome MS, which contains the account of William Rodway (variolated 17 February 1797), could not have been written before the end of February. It was obviously completed in time to be corrected and signed by Jenner on 29 Marsh 1797. The Royal College MS also has the account of Rodway and, like the WI-MS, originally lacked the accounts of Elizabeth and Sarah Wynne. These accounts were later added to the RC-MS and, as these patients were variolated on 28 March 1797, could not have been included before early-mid April.

Close comparison of the texts indicates that the WI-MS was prepared first. In particular, there are instances where passages added by Jenner to the WI-MS are integral features of the RC-MS. An example of this is the important sentence, "This disease has obtained the name of the Cow Pox." "There are also the comments in pencil to be considered, where alterations made by Jenner to the RC-MS correspond to pencilled comments in the WI-MS. It is not possible to determine when the pencilled comments were made, but it is reasonable to suppose that Jenner had made his own obvious corrections before showing the draft to his colleague.

In summary, it seems certain that the basic versions of the two manuscripts were prepared in late February to early March, with the WI-MS actually being prepared first. Jenner corrected the WI-MS and used this to prepare the RC-MS. At about the same time, he showed the corrected WI-MS to a colleague and corrected both manuscripts as a result. Also during this period, he saw (or was shown) the need for more evidence and added two more cases to the RC-MS in early April 1797.

The first leaf of the RC-MS is inscribed in Jenner's hand. "On the Cow-Pox-the original Manuscript". Crookshank, who did not know of the WI-MS, took this inscription at face value. ${ }^{12}$ However, the RC-MS is not the earliest version, and it is possible that Jenner inscribed the copy later, simply to distinguish it from manuscripts of his later monographs on cowpox. ${ }^{13}$ It is interesting to note that the WI-MS was also described as "The Original MS" in an auctioneer's catalogue. ${ }^{14}$ However, because this MS is not in Jenner's hand, it is probably based on an earlier draft by Jenner which has not survived.

SOURCE OF DATA FOR THE PUBLISHED INQUIRY

There is a large measure of agreement between the two manuscripts and the

11 Jenner, op. cit., note 1 above, p. 3.

${ }^{12}$ Crookshank, op. cit., note 2 above.

${ }^{13}$ Edward Jenner, Further observations on the variolae vaccinae, London, Sampson Low, 1799; $A$ continuation of facts and observations relative to the variolae vaccinae or cowpox, London, Sampson Low, 1800.

${ }_{14}$ [F. Mockler], Catalogue of the collection of relics formed by F. Mockler, Esq., London, Puttick \& Simpson, 1894, p. 11. 


\section{The genesis of Edward Jenner's Inquiry of 1798}

published Inquiry, and in general terms it is tempting to regard the manuscripts as drafts of the final version. However, it is clear that Jenner could not have prepared the final account of his early cases without using a third source of information. The most obvious evidence for this is the absence from both manuscripts of the accounts of Walkley, Stinchcombe, and Nelmes.

\section{DISCUSSION}

The published Inquiry was greeted with some opposition and was rejected entirely by some critics. ${ }^{15}$ Consequently, it is of interest to see what evidence Jenner was originally prepared to submit in support of his views.

If one accepts Jenner's motives as honourable, then perhaps "laziness" is a convenient term to cover his faults. ${ }^{16}$ This showed itself in the omission of cases which could have been included originally. However, although these cases appeared in the published monograph, they only increased the amount of circumstantial evidence; the corrected manuscripts contained just one vaccination, that of James Phipps in 1796. Jenner abandoned his original intention to publish his work in the Philosophical Transactions of the Royal Society and, although urged to publish privately in $1797,{ }^{17}$ publication was delayed until the summer of 1798 . The delay made all the difference. The major difference between the manuscripts and the published version is the inclusion in the latter of the important series of arm-to-arm vaccinations done in 1798 . The criticism of Jenner by objective observers for originally basing his theory on just one vaccination is quite justified..$^{18}$

If Jenner's claims were to be accepted and confirmed by others, it was essential that sufficient information be provided, particularly about cowpox and other infections with which it could be confused. In this respect, the manuscripts were deficient. The description of bovine cowpox in the WI-MS is very poor, ${ }^{19}$ and the development of the final form which describes the colour and appearance of the lesion can be followed via additions to the manuscripts. Similarly, the description of human cowpox was improved, and supported by engravings.

Jenner was criticized, particularly by Charles Creighton, for inventing the term "variolae vaccinae", which was used only in the title of the Inquiry and not defined in the text. ${ }^{20}$ Perhaps more surprising was Jenner's reluctance to use the term

${ }^{15}$ The reception received by the Inquiry has recently been discussed at length: Derrick Baxby, Jenner's smallpox vaccine, London, Heinemann Educational Books, 1981, pp. 52-88.

${ }^{16}$ Some did not believe his motives were honourable, see e.g. Charles Creighton, Jenner and vaccination, London, Swan Sonnenschein, 1889. Creighton believed that Jenner had perpetrated a deliberate hoax.

${ }^{17}$ Baron, op. cit., note 6 above, vol. 1, p. 142.

${ }^{13}$ Some biographers have glossed over the importance of the differences between the manuscripts and the published Inquiry, e.g. F. D. Drewitt, The life of Edward Jenner, London, Longmans, 1931, pp. 52-53; Dorothy Fisk, Dr. Jenner of Berkeley, London, Heinemann, 1959, p. 131. Baron, op. cit., note 6 above, vol. 1, pp. 140-143, vol. 2, pp. 167-168, is ambiguous, and was thought by Dixon to be deliberately misleading; C. W. Dixon, Smallpox, London. Churchill, 1962, p. 262.

19 "It appears on the Nipples of the cows in the form of distinct Pustules, which unless a timely remedy is applied frequently degenerate into ulcers." Jenner, op. cit., note 5 above, pp. 3-4.

${ }^{20}$ The term is not used at all in either of the manuscripts, and its use in just the title of the published version may have been a last-minute decision. Creighton, op. cit., note 16 above, pp. 44, 52, referred to Jenner's use of this term as the "startling novelty" and "unblushing invention" which helped to hoodwink the medical profession. 


\section{Baxby}

"cowpox", until prompted by his unknown reviewer. The term was not used at all in the introductory pages of the original WI-MS. As originally planned, Jenner's first use of the term, apart from in the title, would have been on p. 8 in the account of Joseph Merrett (Case 1).

However, if the manuscripts lacked information, it is clear that all Jenner's novel ideas were present from the start, even if some of them were not fully developed. Jenner believed that cowpox was derived from an equine infection, grease, but that it had to be obtained from infected cows in order to be effective in man. This grease theory, and the circumstantial evidence which Jenner thought supported it, was present in full in both manuscripts. The ideas that cowpox provided life-long protection against smallpox but that repeated cases of cowpox could occur were also discussed in both manuscripts, although more information is provided in the published Inquiry.

Jenner's concept of "true" and "spurious" cowpox was crucial for the proper development of vaccination. In its final form it was complex and multifaceted although the idea was still incompletely formulated in the published Inquiry. A detailed analysis of the subject has recently been published, ${ }^{21}$ but briefly the concept concerned "true" cowpox, i.e. that which would confer immunity to smallpox, and "spurious" cowpox, i.e. anything which might be used in error and which would not immunize. One type of spurious material was genuine cowpox which had become ineffective due to improper storage. However, this was not discussed in connexion with cowpox at all, but as a danger sometimes encountered with inoculated smallpox. This argument is complete in the two manuscripts but was incorporated into a long footnote to Case 3 rather than in the text proper, as in the published version.

A second type of spurious cowpox, bovine infections which might be mistaken for cowpox, was discussed in the Inquiry in a long footnote to Case 1. As such, it might be considered an afterthought, but most of the text is present in a similar footnote in the RC-MS. However, the account in the WI-MS is much less coherent and is added after the text proper, partly in Jenner's hand and partly in Davies's. Evidently, Jenner had some difficulty in presenting this topic initially.

The terms "true" and "spurious" cowpox were not used in either manuscript or in the published footnote. They were introduced at the very end of the published Inquiry without explanation but with a note to refer to the footnote discussed above. Jenner was soon to deal fully with true and spurious cowpox in his next pamphlet, ${ }^{22}$ and it is important to appreciate how crucial the concept was. Vaccination could never have been introduced when it was without a thorough appreciation of the problems caused by other bovine infections and deteriorated vaccine.

Finally, it is worth noting that the footnote to the account of Mary Barge (Case 4), which contains the first description of what was to be known as anaphylaxis, is present in both manuscripts, although Jenner added one sentence to the WI manuscript. ${ }^{23}$

\footnotetext{
${ }^{21}$ Baxby, op. cit., note 15 above, pp. 134-149.

22 Jenner, op. cit., note 13 above, pp. 4-28.

23 "Indeed it becomes almost a criterion by which we can determine whether the infection will be received or not." Jenner, op. cit., note 5 above, p. 15.
} 
Perhaps Jenner's major contribution was the interconnected series of ideas concerned with cowpox and immunity to smallpox rather than the somewhat limited evidence on which the ideas were based. Some ideas were brilliant, e.g. the basic idea that cowpox protected against smallpox, and the crucial concept of true and spurious cowpox. Others were misguided, e.g. that the virus had to pass from horse to cow, and that immunity was lifelong. However, in view of the delay between the writing of the manuscripts and the publication of the Inquiry, and of the advice he may have received during this period, it is important to note that all the ideas were present in the earliest manuscript. Some were improved upon in the published Inquiry and there is an interesting contrast here between the grease theory, which is present in full in the manuscripts, and the spurious cowpox theory which was not fully developed even in the published version.

The published Inquiry is, of course, better in all respects than the manuscripts. However, it seems clear that whatever advice Jenner was given in the missing year, his colleagues could only ask for expansion and clarification of ideas which were Jenner's originally.

\section{ACKNOWLEDGEMENTS}

Passages from the WI-MS and RC-MS are quoted by courtesy of the Wellcome Trustees and of the President and Council of the Royal College of Surgeons of England. E. J. Freeman and E. H. Cornelius kindly arranged access to the manuscripts and R. Price and I. Lyle made helpful suggestions. William LeFanu kindly allowed access to information in the then unpublished second edition of his Bio-bibliography of Jenner. 